\title{
Flesh-Colored Papule in the Nose of a Child
}

Stanton Y. Miller, MD; Alex Kane, MD; Travis W. Vandergriff, MD

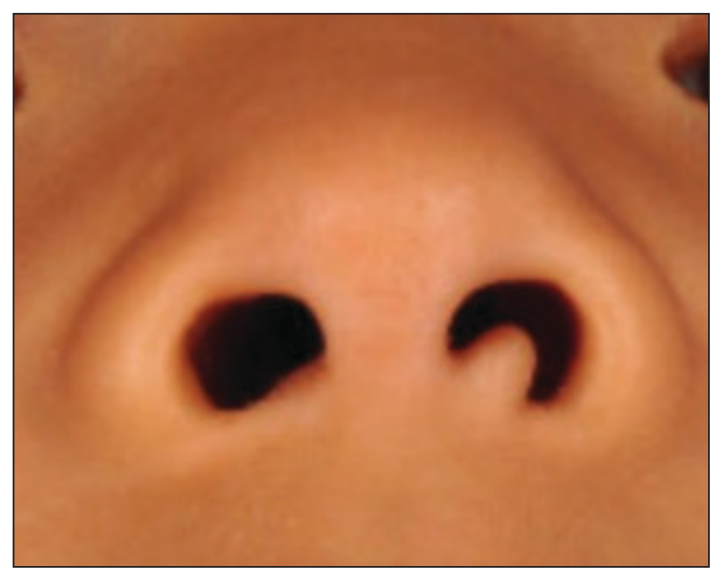

A 4-year-old girl presented to our clinic with an asymptomatic flesh-colored papule in the left nostril. The lesion had been present since birth and grew in relation to the patient with no rapid changes. There had been no pigmentation changes and no bleeding, pain, or itching. The patient's birth and developmental history were normal. Physical examination revealed a singular, $10 \times 5-\mathrm{mm}$, flesh-colored, pedunculated mass on the left nasal sill. There were no additional lesions present. An excisional biopsy was performed and submitted for pathologic diagnosis.

\section{WHAT'S YOUR DIAGNOSIS?}
a. accessory tragus
b. connective tissue nevus
c. fetal rhabdomyoma
d. fibrous hamartoma of infancy
e. striated muscle hamartoma 


\section{THE DIAGNOSIS:}

\section{Striated Muscle Hamartoma}

H istopathologic evaluation revealed a dome-shaped papule with a center composed of mature striated muscle bundles, vellus hairs, sebaceous lobules, and nerve twigs (Figure) consistent with a diagnosis of striated muscle hamartoma $(\mathrm{SMH})$.

Striated muscle hamartoma was first described in 1986 by Hendrick et $\mathrm{al}^{1}$ with 2 cases in neonates. Biopsies of the lesions taken from the upper lip and sternum showed a characteristic histology consisting of dermal striated muscle fibers and nerve bundles in the central core of the papules associated with a marked number of adnexa. In 1989, the diagnosis of rhabdomyomatous mesenchymal hamartoma was described, which showed similar findings. ${ }^{2}$ Cases reported since these entities were discovered have used the terms striated muscle hamartoma and rhabdomyomatous mesenchymal hamartoma interchangeably. ${ }^{3}$

Most commonly found on the head and neck, SMH has now been observed in diverse locations including the sternum, hallux, vagina, and oral cavity. ${ }^{1-15}$ Many reported cases describe lesions around or in the nose. ${ }^{4,7,8}$ Multiple congenital anomalies have been described alongside $\mathrm{SMH}$ and may be associated with this entity including amniotic bands, cleft lip and palate, coloboma, and Delleman syndrome. ${ }^{1,3,4}$ Almost all of the lesions present as a sessile or pedunculated papule, polyp, nodule, or plaque measuring from $0.3 \mathrm{~cm}$ up to $4.9 \mathrm{~cm}$ and typically are present since birth. ${ }^{3,5,15}$ However, there are a few cases of lesions presenting in adults with no prior history. $5,6,15$

Microscopically, SMH is defined by a dermal lesion with a core comprised of mature skeletal muscle admixed with adipose tissue, adnexa, nerve bundles, and fibrovascular tissue. ${ }^{1}$ There are other entities that should be considered before making the diagnosis of SMH. Other hamartomas such as accessory tragus, connective tissue nevus, fibrous hamartoma of infancy, and nevus lipomatosis may present similarly; however, these lesions classically lack skeletal muscle. Benign triton tumors, or neuromuscular hamartomas, are rare lesions composed of skeletal muscle and abundant, intimately associated neural tissue. Neuromuscular hamartomas frequently involve large nerves. ${ }^{16}$ Rhabdomyomas also should be considered. Adult rhabdomyomas are composed of eosinophilic polygonal cells with granular cytoplasm and occasional cross-striations. Fetal rhabdomyomas have multiple histologic types and are defined by a variable myxoid stroma, eosinophilic spindled cells, and rhabdomyocytes in various stages of maturity. Genital rhabdomyomas histopathologically appear similar to fetal rhabdomyomas but are confined to the genital region. The skeletal muscle present in rhabdomyomas typically is less differentiated. ${ }^{17}$
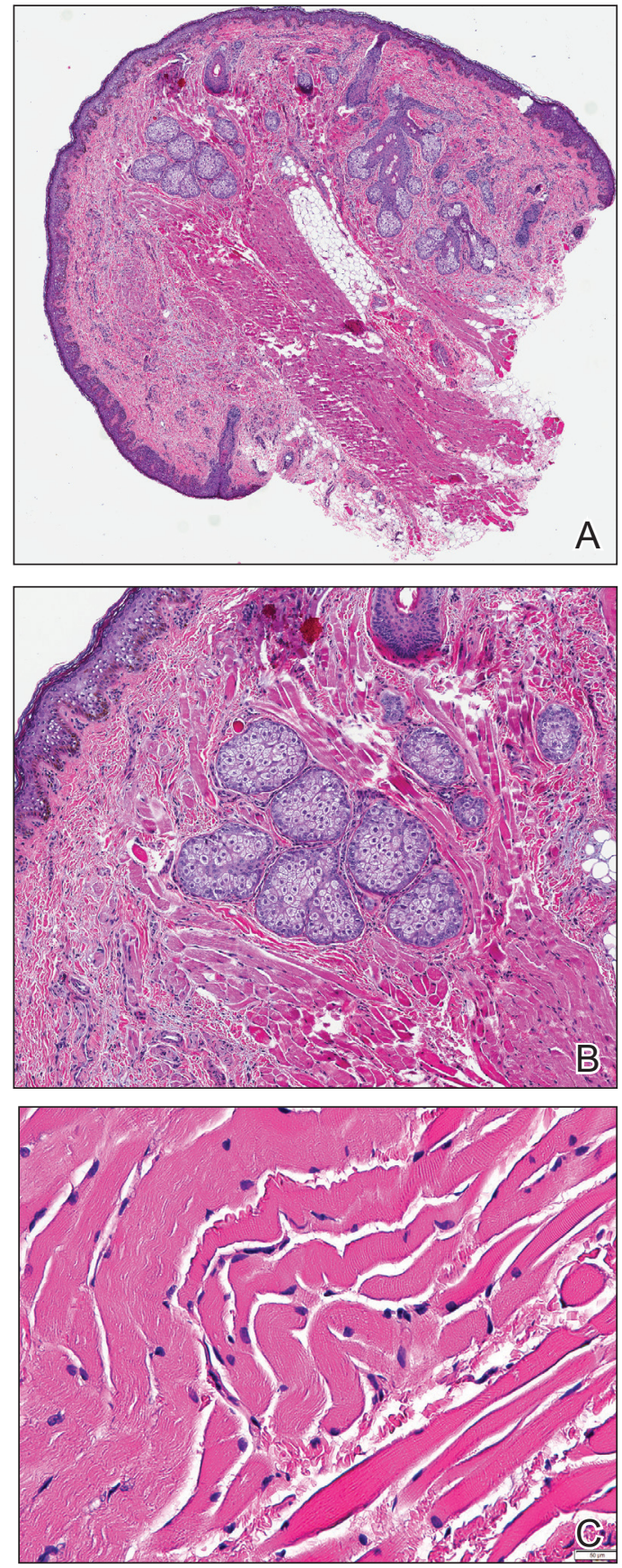

A, Scanning magnification revealed a dome-shaped papule with dense bundles of skeletal muscle in its core and pilosebaceous units $(H \& E$, original magnification $\times 20)$. B, Bundles of striated muscle extended through the reticular dermis into the papillary dermis and surrounded the adnexal units (H\&E, original magnification $\times 100)$. $\mathrm{C}$, Skeletal muscle with peripheral nuclei and striations (H\&E, original magnification $\times 400)$. 
Mature skeletal bundles should be a dominant component of the lesion before diagnosing $\mathrm{SMH}$.

Typically presenting as congenital lesions in the head and neck region, papules with a dermal core of mature skeletal muscle associated with adnexa and nerve twigs should prompt consideration of a diagnosis of $\mathrm{SMH}$ or rhabdomyomatous mesenchymal hamartoma. These lesions are benign and usually are cured with complete excision.

\section{REFERENCES}

1. Hendrick SJ, Sanchez RL, Blackwell SJ, et al. Striated muscle hamartoma: description of two cases. Pediatr Dermatol. 1986;3:153-157.

2. Mills AE. Rhabdomyomatous mesenchymal hamartoma of skin. Am J Dermatopathol. 1989;1:58-63.

3. Rosenberg AS, Kirk J, Morgan MB. Rhabdomyomatous mesenchymal hamartoma: an unusual dermal entity with a report of two cases and a review of the literature. J Cutan Pathol. 2002;29:238-243.

4. Sánchez RL, Raimer SS. Clinical and histologic features of striated muscle hamartoma: possible relationship to Delleman's syndrome. J Cutan Pathol. 1994;21:40-46.

5. Chang CP, Chen GS. Rhabdomyomatous mesenchymal hamartoma: a plaque-type variant in an adult. Kaohsiung J Med Sci. 2005;21:185-188.

6. Harris MA, Dutton JJ, Proia AD. Striated muscle hamartoma of the eyelid in an adult woman. Ophthalmic Plast Reconstr Surg. 2008;24:492-494
7. Nakanishi H, Hashimoto I, Takiwaki H, et al. Striated muscle hamartoma of the nostril. J Dermatol. 1995;22:504-507.

8. Farris PE, Manning S, Veatch F. Rhabdomyomatous mesenchymal hamartoma. Am J Dermatopathol. 1994;16:73-75.

9. Grilli R, Escalonilla P, Soriano ML, et al. The so-called striated muscle hamartoma is a hamartoma of cutaneous adnexa and mesenchyme, but not of striated muscle. Acta Derm Venereol. 1998;78:390.

10. Sampat K, Cheesman E, Siminas S. Perianal rhabdomyomatous mesenchymal hamartoma. Ann R Coll Surg Engl. 2017;99:E193-E195.

11. Brinster NK, Farmer ER. Rhabdomyomatous mesenchymal hamartoma presenting on a digit. J Cutan Pathol. 2009;36:61-63.

12. Han SH, Song HJ, Hong WK, et al. Rhabdomyomatous mesenchymal hamartoma of the vagina. Pediatr Dermatol. 2009;26:753-755.

13. De la Sotta P, Salomone C, González S. Rhabdomyomatous (mesenchymal) hamartoma of the tongue: report of a case. J Oral Pathol Med. 2007;36:58-59.

14. Magro G, Di Benedetto A, Sanges G, et al. Rhabdomyomatous mesenchymal hamartoma of oral cavity: an unusual location for such a rare lesion. Virchows Arch. 2005;446:346-347.

15. Wang $Y$, Zhao H, Yue $X$, et al. Rhabdomyomatous mesenchymal hamartoma presenting as a big subcutaneous mass on the neck: a case report. J Med Case Rep. 2014;8:410.

16. Amita $\mathrm{K}$, Shankar SV, Nischal KC, et al. Benign triton tumor: a rare entity in head and neck region. Korean J Pathol. 2013;47:74-76.

17. Walsh S, Hurt M. Cutaneous fetal rhabdomyoma: a case report and historical review of the literature. Am J Surg Pathol. 2008;32:485-491. 